\title{
Stigma-related Factors and their Effects on Health-care Workers during COVID-19 Pandemics in Turkey: A Multicenter Study
}

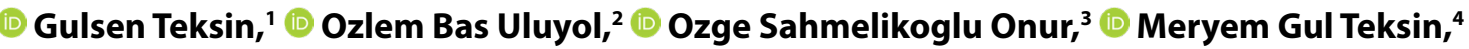 \\ (D) Haci Mustafa Ozdemir ${ }^{5}$
}

'Department of Psychiatry, University of Health Sciences Turkey, Sisli Hamidiye Etfal Teaching and Resarch Hospital, Istanbul, Turkey ${ }^{2}$ Department of Psychiatry, University of Health Sciences Turkey, Sancaktepe Sehit Prof. Dr. Ilhan Varank Training and Research Hospital, Istanbul, Turkey

${ }^{3}$ Department of Psychiatry, University of Health Sciences Turkey, Mazhar Osman Bakirkoy Mental Health and Neurological Diseases Training and Research Hospital, Istanbul, Turkey

${ }^{4}$ Department of Psychiatry, University of Health Sciences Turkey, Dr. Abdurrahman Yurtaslan Ankara Onkoloji Training and Research Hospital, Ankara, Turkey

${ }^{5}$ Department of Orthopedic, University of Health Sciences Turkey, Sisli Hamidiye Etfal Teaching and Resarch Hospital, Istanbul, Turkey

\begin{abstract}
Objectives: Infectious diseases-related stigmatization is a common feature in health-care workers (HCWs). This study aims to evaluate the factors associated with stigmas and the effects of stigmatization in HCWs during the coronavirus disease (COVID-19) pandemic.

Methods: This study was conducted by an anonymous online survey of 452 actively working HCWs during the COVID-19 pandemic. All subjects provided informed consent electronically before registration and completed the sociodemographic data form, a questionnaire about COVID-19 pandemics, a COVID-19 stigmatization questionnaire for health-care workers, a hospital anxiety depression scale form (HADS), a psychological well-being scale form, the World Health Organization Quality of Life Scale short form (WHO-QOL BREF) and Coping Styles Scale brief form (CBSS-BF).

Results: Perception of stigma score was significantly higher among HCWs with one or more of the following characteristics: they had worked with patients with COVID-19 (+) but had no specific training related to coronavirus, experienced COVID-19 symptoms themselves, delayed testing due to anxiety, received psychological support during COVID-19 pandemics, suffered from a psychological disorder, or had suicidal thoughts/attempts before or during the COVID-19 pandemic $(p<0.05)$. A statistically significant positive correlation was observed between the perception of stigmatization score and HAD-S ( $p<0.05$ ). A statistically significant negative correlation was observed between the perception of the stigmatization score and the Psychological Well-Being Score, CSS-BF problem-focused coping and emotion-focused coping, and all subscales of WHOQOL-BRIEF $(p<0.05)$.

Conclusion: The findings of our study showed that the negative perception of stigma in HCWs could affect their psychological well-being and life satisfaction. During the pandemic, it is necessary to prevent stigmatizing HCWs and improve coping strategies to protect their mental health and increase their life quality.

Keywords: COVID-19; coronavirus disease; coping style; psychological well-being; stigmatization; quality of life.

Please cite this article as "Teksin G, Bas Uluyol O, Sahmelikoglu Onur O, Teksin MG, Ozdemir HM. Stigma-related Factors and their Effects on Health-care Workers during COVID-19 Pandemics in Turkey: A Multicenter Study. Med Bull Sisli Etfal Hosp 2020;54(3):281-290".
\end{abstract}

Address for correspondence: Gulsen Teksin, MD. Saglik Bilimleri Universitesi Sisli Hamidiye Etfal Egitim ve Arastirma Hastanesi,

Psikiyatri Klinigi, Istanbul, Turkey

Phone: +90 5069206664 E-mail: teksingulsen@gmail.com

Submitted Date: August 08, 2020 Accepted Date: August 14, 2020 Available Online Date: September 07, 2020

${ }^{\circ}$ Copyright 2020 by The Medical Bulletin of Sisli Etfal Hospital - Available online at www.sislietfaltip.org

OPEN ACCESS This is an open access article under the CC BY-NC license (http://creativecommons.org/licenses/by-nc/4.0/). 
$T^{\mathrm{h}}$ he coronavirus disease (COVID-19) pandemic spread across the planet, quarantined populations, filled hospitals with patients, and resulted in an increase in global mortality. Concerning mental health effects from such a pandemic, one must consider the potential psychological impact of quarantine on the general population and individuals suffering from mental disorders as well as the impact on health-care workers (HCWs). ${ }^{[1]}$

HCWs face many challenges, such as direct exposure to patients and the risk of infection, physical exhaustion, reorganization of work spaces, and adaptation to rigid work schedules. As a result, HCWs are at increased risk of developing mental disorders.

Assessing the psychological impacts of the pandemic outbreaks on health professionals is nothing new. Several surveys of hospital staff revealed that HCWs had anxiety symptoms with concerns focused on the viral infection itself, the fear of infecting relatives, and the attendant damage to their health. ${ }^{[2,3]}$ These studies showed that being in contact with infected patients could increase the anxiety linked to the infection and feelings of possible psychosomatic exhaustion. ${ }^{[2,4]}$ Other factors that increase the risk of psychiatric symptoms in HCWs include: a lack of counseling and psychological support, feeling the impact of social isolation, viral-infection-related stigma, fear of infecting their children, and fear of family stigmatization and the negative effects on their children's social and educational life. ${ }^{[2,4]}$

Like other pandemics, health-care professionals working in the middle of the COVID-19 pandemic have been experiencing mental health problems. In a study conducted with health-care professionals working with patients with COVID-19, a significant proportion experienced symptoms of anxiety, depression, and insomnia; and more than $70 \%$ experienced psychological distress. ${ }^{[5]} \mathrm{A}$ recent study involving 1.563 health professionals reported that more than half $(50.7 \%)$ of the participants reported depressive symptoms: $44.7 \%$ anxiety and $36.1 \%$ sleep disturbance. ${ }^{[6]}$ Insufficient information about the COVID-19 pandemic will contribute to the potential psychological impact on $\mathrm{HCWs} .{ }^{[7]}$

Stigma is a concern that affects the quality of life and should be addressed among HCWs related to infectious disease. ${ }^{[8,9]}$ Studies showed that those HCWs felt not only uncertainty and stigmatization but also contemplated resigning from their positions ${ }^{[8]}$ Approximately $20 \%$ of the HCWs affected by the SARS outbreak in Taiwan felt stigmatized and ostracized by their neighbors. ${ }^{[9]}$ In a study conducted with nurses caring for MERS CoV patients, it was found that stigma has both direct and indirect stress-related effects on mental health. ${ }^{[10]}$ Stigmatization has also been as a possible source of stress. ${ }^{[11]}$ In line with this, recent studies have presented that stigmatized people living with infectious diseases, and the HCWs caring for them, experience depression, anxiety, and a lower quality of life. ${ }^{[12]}$ During the COVID-19 pandemic, changing working and living conditions (isolation and separation from family), stigma perception, and physical and mental health conditions of HCWs can affect their quality of life. Overall, there are many different workrelated stressors that negatively affect the quality of life in hospital workers. ${ }^{[13]}$

People use coping mechanisms to deal with stressful events. ${ }^{[14]}$ Two general coping strategies have been identified: one strategy is problem-focused coping, its purpose is to solve problems; the other strategy is emotion-focused coping, which aims to reduce emotional distress. ${ }^{[15]}$ Although infectious diseases have a huge impact on mental health and people's emotional responses, not everyone experiences the same degree of impact. ${ }^{[16]}$ Based on a recent systematic review of the impact of the disaster on the mental health of $\mathrm{HCWs}$, the identified common risk factors for developing psychological morbidities include a lack of social support and communication, maladaptive coping, and a lack of training ${ }^{[17]}$ In addition to the impact of COVID-19 on people's emotions, people's coping strategies will also change. The mental and physical health of HCWs may be affected during the pandemic period. Perceptions of stigma may occur. All of this may affect the quality of life of health-care professionals. In this challenging scenario, it is necessary to take measures to protect the mental health of HCWs and increase their quality of life. This study aims to evaluate stigma-related factors and their effects on mental health and life quality in health-care workers during the COVID-19 pandemic in Turkey. We also aim to investigate the relationship between the perception of stigmatization and coping strategies in HCWs.

\section{Methods}

This cross-sectional study was conducted between 20 May 2020 and 10 June 2020 by applying an anonymous online survey to HCWs who were actively working during the COVID-19 pandemic. All subjects provided informed consent electronically before registration. Only subjects who agreed to participate voluntarily were included in this study, and subjects could quit the process at any time. Only one response per person to the questionnaire was permitted. Incomplete surveys were not included in this study.

This study was approved by the Clinical Research Ethics Committee of University of Health Sciences, Sisli Hamidiye Etfal Research and training hospital (approval number: 2782; approval date: 12/05/2020). 


\section{Research Tools}

The questionnaire consisted of five parts: online informed consent, sociodemographic data form, the questionnaire about COVID-19 pandemics, COVID-19 stigmatization questionnaire for health care workers and rating scales, including Hospital anxiety depression scale, Psychological well-being scale, World Health Organization Quality of Life Scale-Short form (WHO-QOL BREF) and Coping Styles Scale Brief Form (CBSS-BF).

Sociodemographic Data Form: The researchers prepared this form to assess the participants' sociodemographic characteristics. It includes questions about the participants' age, gender, marital status, education, occupation and type of worked hospital.

COVID-19 Questionnaire: This questionnaire was prepared by the researcher to evaluate the working conditions, COVID-19 exposures, and the physical and mental health of the participants after the COVID-19 pandemic. The answer to each question was yes or no. The form contains the following questions:

1. Do you work with COVID-19 (+) patients?

2. If you work with COVID-19 (+) patients, did you receive previous training?

3. Do you think you have enough medical information about COVID-19?

4. Do you think you have enough medical equipment?

5. Have your working hours changed during the COVID-19 pandemic?

6. Have you been experiencing COVID-19 symptoms?

7. Has your COVID-19 test been administered?

8. Have you delayed testing due to anxiety?

9. Have you been quarantined or in self-isolation?

10. Is there anyone with COVID-19 (+) in your family?

11. Is there anyone in your family who died from COVID-19?

12. Is there anyone in the COVID-19 risk group among individuals living together?

13. Do you have access to psychological support during the COVID-19 pandemic?

14. Do you have a psychological disorder?

15. Is there anyone with a psychological disorder in your family?

16. Did you attempt suicide or have suicidal thoughts before the COVID-19 pandemic?

17. Have you attempted suicide or had suicidal thoughts during the COVID-19 pandemic?

COVID-19 Stigmatization Questionnaire for Health-
Care Workers: This form, prepared by the researcher, consists of 15 statements to identify the events experienced by health-care professionals during the pandemic and the feelings and thoughts they have experienced. There are five response options for each question on the form, scored between 0 and 4 (0: strongly disagree, 1: disagree, 2: indecisive, 3: agree, 4: strongly agree). Questions in the survey are scored in ascending order, but only the eleventh question is scored in descending order. As the total score gets higher, the perception of stigma increases.

Hospital Anxiety Depression Scale (HADS): The Hospital Anxiety and Depression Scale (HADS) was developed in 1983 by Zigmond et al. ${ }^{[18]}$ to evaluate mood disorders. It can be easily used in the community and hospital areas. In the scale, psychiatric symptoms are tried to separate from physical disorders. HADS consists of 14 items and oddnumbered items investigate anxiety and even-numbered items investigate the depression. The scale is a self-report, four-point Likert -type and the scores of the items are between 0-3. In 1997, Turkish validity and reliability of the scale was performed by Aydemir et al. ${ }^{[19]}$

Psychological Well-being Scale: Psychological well-being is a concept that includes support human well-being, from positive relationships to having a purposeful life. It was developed by Dinner in 2009, and the Turkish validity and reliability study was carried out by Telef in $2013 .{ }^{[20,21]}$ It is a seven-point Likert-type scale with one sub-dimension consisting of 8 items. The score obtained from the scale varies between 8-56. High score shows that the person has many psychological resources and powers.

World Health Organization Quality of Life Scale-Short form (WHOQOL-BRIEF): It is a self-report tool that allows us to quantitatively evaluating the quality of life. The scale consists of 27 questions and each question is scored between 1 and 5. It has 4 subscales: 1. Physical area, 2. Mental area, 3. Social relations area, 4. Environmental area. Question 27 is only available in the Turkish version of the scale and, when used, the environmental score is called the environment-TR. The quality of life increases as the score gets higher. ${ }^{[22]}$

Coping Styles Scale Brief Form (CSS-BF): Coping Styles Scale Brief Form (CSS-BF) is a short form developed by Carver (1997) by revising its long-form. ${ }^{[23]}$ Coping Strategies Short Form consists of 28 questions and 14 subscales. The answers to each item are from "I never do this" to "I do this a lot" between 1-4 is evaluated. The subscales of the form are 14 and include;

1. Using Instrumental Social Support,

2. Suppression of Competing Activities, 
3. Restraint Coping,

4. Planning,

5. Positive Reinterpretation,

6. Turning to religion,

7. Humor,

8. Using Emotional Social Support,

9. Acceptance,

10. Mental Disengagement,

11. Focus on and Venting of Emotions,

12.Denial,

13. Behavioral Disengagement,

14. Substance Use.

The sum of the scores of the first four subscales gives the Problem-focused coping score, the sum of the scores of 5.9. Subscales give the emotion-focused coping score; the sum of the scores of last five subscales gives the non-functional coping score. Turkish validity and reliability studies were conducted by Bacanlı et al. ${ }^{[24]}$

\section{Statistical Analysis}

Statistical analysis was performed using SPSS 22.0 for Windows statistical software. p-value $<0.05$ was considered to be statistically significant. Descriptive statistical methods, including mean, standard deviation, minimum and maximum, frequency and ratio values, were used. Distribution of the variables was detected with the Kolmogorov-Smirnov test. Independent samples t-test, in addition to Mann-Whitney $\mathrm{U}$ test, was used for the quantitative independent data. The chi-square test was used for the analysis of qualitative independent data and the Fisher test was used when the chi-square test conditions were not met. One-way ANOVA and post hoc analyzes were used in assessing two or more independent groups. Spearman correlation analysis was used for correlation analysis.

\section{Results}

In our study, we enrolled 452 HCWs whom 153 (33.8\%) males and $299(66.2 \%)$ females between 21 and 70 with an average age of 35.8 \pm 8.9 .247 (54.6\%) were married, 178 (39.4\%) were single and 27 (6.0\%) were divorced/widow.318 (70.4\%) HCWs had worked in a pandemic hospital. Table 1 outlines the baseline characteristics of the participants. The scores of Covid-19 stigmatization questionnaire for HCWs, HAD-S, Psychological Well-being Scale, WHOQOL-BRIEF and CBSS-BF applied to the participants are given in Table 1.

Data on the relationship between the sociodemographic characteristics of the participants and the perception of
Table 1. Sociodemographic Characteristics and Perception of Stigma Score, Psychological Well-Being Scale, HAD-S, WHOQOL-BRIEF, CSS-BF Scale Scores of the Participants

\begin{tabular}{|c|c|c|c|}
\hline \multirow{3}{*}{ Age } & \multirow[t]{2}{*}{ Min.-Max. } & \multicolumn{2}{|c|}{ Mean \pm SD } \\
\hline & & $\mathbf{n}$ & $\%$ \\
\hline & \multirow[t]{4}{*}{$21.0-70.0$} & \multicolumn{2}{|c|}{$35.8 \pm 8.9$} \\
\hline \multicolumn{3}{|l|}{ Gender } & \\
\hline Female & & 299 & 66.2 \\
\hline Male & & 153 & 33.8 \\
\hline \multicolumn{4}{|l|}{ Marital status } \\
\hline Single & \multicolumn{2}{|r|}{178} & 39.4 \\
\hline Married & \multicolumn{2}{|r|}{247} & 54.6 \\
\hline Divorced/Widow & \multicolumn{2}{|r|}{27} & 6.0 \\
\hline Number of children & $0.0-4.0$ & \multicolumn{2}{|c|}{$0.8 \pm 0.9$} \\
\hline \multicolumn{4}{|l|}{ Whom live with during outbreak } \\
\hline With family & & 292.0 & 64.6 \\
\hline Alone at home & & 103.0 & 22.8 \\
\hline Alone at hotel & & 18.0 & 4.0 \\
\hline Others & & 39.0 & 8.6 \\
\hline \multicolumn{4}{|l|}{ Education } \\
\hline High school & & 20.0 & 4.4 \\
\hline Pre-bachelor & & 35.0 & 7.7 \\
\hline Bachelor & & 121.0 & 26.8 \\
\hline Master & & 58.0 & 12.8 \\
\hline $\mathrm{PhD}$ & & 218.0 & 48.2 \\
\hline \multicolumn{4}{|l|}{ Occupation } \\
\hline Doctor & & 248 & 54.9 \\
\hline Dentist & & 15 & 3.3 \\
\hline Nurse & & 110 & 24.3 \\
\hline Psychologist/Pedagogue & & 8 & 1.8 \\
\hline Health technician & & 32 & 7.1 \\
\hline Secretary & & 20 & 4.4 \\
\hline Laboratory Assistant & & 5 & 1.1 \\
\hline Security guard & & 8 & 1.8 \\
\hline Others & & 6 & 1.3 \\
\hline \multicolumn{4}{|l|}{ Type of hospital } \\
\hline Pandemic hospital & & 318 & 70.4 \\
\hline Non-pandemic Hospital & & 134 & 29.6 \\
\hline Perception of Stigma Score & $0.0-50.0$ & & \\
\hline Psychological Well-Being Scale & $8.0-56.0$ & & \\
\hline \multicolumn{4}{|l|}{ HAD-S } \\
\hline HAD-A & $0.0-21.0$ & & \\
\hline HAD-D & $0.0-21.0$ & & \\
\hline \multicolumn{4}{|l|}{ WHOQOL-BRIEF } \\
\hline General area & $2.0-10.0$ & & \\
\hline Physical area & $8.0-35.0$ & & \\
\hline Mental area & $6.0-30.0$ & & \\
\hline Social relations area & $3.0-15.0$ & & \\
\hline Environment area & $13.0-44.0$ & & \\
\hline \multicolumn{4}{|l|}{ CSS-BF } \\
\hline Problem-focused coping & $16.0-32.0$ & & \\
\hline Using Instrumental Social Support & $2.0-8.0$ & & \\
\hline Suppression of Competing Activities & $2.0-8.0$ & & \\
\hline
\end{tabular}


Table 1. CONT.

\begin{tabular}{|c|c|c|c|}
\hline & \multirow[t]{2}{*}{ Min.-Max. } & \multicolumn{2}{|c|}{ Mean \pm SD } \\
\hline & & $\mathbf{n}$ & $\%$ \\
\hline Restraint Coping & $2.0-8.0$ & $5.4 \pm 1.2$ & \\
\hline Planning & $3.0-8.0$ & $6.7 \pm 1.2$ & \\
\hline Emotion-focused coping & $14.0-40.0$ & $28.9 \pm 4.4$ & \\
\hline Positive Reinterpretation & $2.0-8.0$ & $6.1 \pm 1.4$ & \\
\hline Turning to religion & $2.0-8.0$ & $5.9 \pm 2.0$ & \\
\hline Humor & $2.0-8.0$ & $4.9 \pm 1.7$ & \\
\hline Using Emotional Social Support & $2.0-8.0$ & $5.7 \pm 1.4$ & \\
\hline Acceptance & $2.0-8.0$ & $6.4 \pm 1.3$ & \\
\hline Non-functional coping & $10.0-35.0$ & $20.7 \pm 4.0$ & \\
\hline Mental Disengagement & $2.0-8.0$ & $5.0 \pm 1.4$ & \\
\hline Focus on and Venting of Emotions & $2.0-8.0$ & $5.7 \pm 1.4$ & \\
\hline Denial & $2.0-8.0$ & $3.6 \pm 1.4$ & \\
\hline Behavioral Disengagement & $2.0-8.0$ & $3.8 \pm 1.4$ & \\
\hline Substance Use & $2.0-8.0$ & $2.7 \pm 1.3$ & \\
\hline
\end{tabular}

Min: Minimum; Max: Maximum; SD: Standard deviation; n: number of participants; HAD-S: Hospital anxiety depression scale; HAD-A: Anxiety subscale of hospital anxiety depression scale; HAD-D: Depression subscale of hospital anxiety depression scale; WHOQOL-BRIEF: World Health Organization Quality of Life Scale-Short form; CSS-BF: Coping Styles Scale Brief Form.

stigmatization score are presented in the Table 2.

Perception of stigma score was significantly higher in healthcare professionals, who are working with the COVID-19 (+) patients, did not receive training before working with COVID-19 patients, experienced COVID-19 symptoms, delayed testing due to anxiety, got psychological support during COVID-19 pandemics, had a psychological disease, had suicidal thought/attempt before or during the COVID-19 pandemic than individuals who did not $(p<0.05)$ (Table 3).

The data on the correlations between the stigma perception scores of the participants and the HAD-S, Psychological well-being scale, CSS-BF and WHOQOL-BRIEF scores are given in Tables 4, 5 and 6.

A statistically significant positive correlation was observed between the perception of stigmatization score and HAD-A, HAD-D. A statistically significant negative correlation was observed between the perception of stigmatization score and Psychological Well-Being Score ( $p<0.05)$ (Table 4).

A statistically significant negative correlation was observed between the perception of stigmatization score and all subscales of WHOQOL-BRIEF ( $p<0.05)$ (Table 5).

Correlations between the perception of stigma and CSS-BF subscales are given in Table 5 . A statistically significant negative correlation was observed between the perception of stigmatization score and CSS-BF problem-focused coping and emotion focusing coping $(\mathrm{p}<0.05)$. A statistically signif-
Table 2. The relationship of the sociodemographic characteristics with the perception of stigma score

\begin{tabular}{|c|c|c|c|c|}
\hline & $\mathbf{n}$ & Min.-Max. & Mean \pm SD & $\mathbf{p}$ \\
\hline \multicolumn{5}{|l|}{ Gender } \\
\hline Female & 299 & $0.0-50.0$ & $18.1 \pm 10.5$ & $0.001^{m}$ \\
\hline Male & 153 & $0.0-49.0$ & $14.8 \pm 9.4$ & \\
\hline \multicolumn{5}{|l|}{ Marital status } \\
\hline Single & 247 & $0.0-50.0$ & $16.8 \pm 10.1$ & 0.915 \\
\hline Married & 178 & $0.0-46.0$ & $17.3 \pm 10.2$ & \\
\hline Divorced/Widow & 27 & $0.0-43.0$ & $17.5 \pm 12.4$ & \\
\hline \multicolumn{5}{|l|}{$\begin{array}{l}\text { Whom live with during } \\
\text { outbreak }\end{array}$} \\
\hline With family & 307 & $0.0-50.0$ & $17.0 \pm 9.9$ & 0.179 \\
\hline Alone at home & 104 & $0.0-46.0$ & $18.0 \pm 11.1$ & \\
\hline Alone at hotel & 18 & $3.0-39.0$ & $16.2 \pm 11.1$ & \\
\hline Others & 23 & $4.0-33.0$ & $13.1 \pm 9.4$ & \\
\hline \multicolumn{5}{|l|}{ Education } \\
\hline High school & 20 & $1.0-33.0$ & $12.5 \pm 9.4$ & 0.508 \\
\hline Pre-bachelor & 35 & $3.0-36.0$ & $18.6 \pm 9.0$ & \\
\hline Bachelor & 121 & $0.0-50.0$ & $19.0 \pm 10.6$ & \\
\hline Master & 58 & $3.0-41.0$ & $18.3 \pm 10.8$ & \\
\hline $\mathrm{PhD}$ & 218 & $0.0-49.0$ & $15.7 \pm 9.9$ & \\
\hline \multicolumn{5}{|l|}{ Type of hospital } \\
\hline Pandemic hospital & 323 & $0.0-50.0$ & $17.3 \pm 10.1$ & $0.409^{t}$ \\
\hline Non-pandemic hospital & 128 & $0.0-43.0$ & $16.4 \pm 10.7$ & \\
\hline
\end{tabular}

${ }^{\mathrm{m} M a n n-W h i t n e y} \mathrm{U}$ test/ ${ }^{\mathrm{t}}$ Student's t-test; One-way Anova; Post hoc: tukey. Min: Minimum; Max: Maximum; SD: Standard deviation; n: number of participants; $p$-value of $<0.05$ was considered as statistically significant and shown in bold.

icant positive correlation was observed between the perception of stigmatization score and CSS-BF non-functional coping $(p<0.05)$ (Table 6).

\section{Discussion}

The present investigation focuses on the perception of stigma and related features in HCWs who have one or more of the following characteristics: they have been working with COVID-19 (+) patients, have no training related to COVID-19, have been experiencing COVID-19 symptoms, are receiving psychological support, and had a psychological disorder before and during COVID-19 pandemic. HCWs with the aforementioned characteristics expected to experience higher levels of stigmatization increased anxiety and depression and decreased quality of life and well-being. Moreover, HCWs with higher levels of problem-focused and emotion-focused coping had lower perceptions of stigma.

Stigmatization is a common problem that people with infectious diseases and mental disorders often experience and have difficulty overcoming. ${ }^{[25]}$ In line with this, we found that the HCWs who perceived higher degrees of stig- 
Table 3. The relationship of health-care workers characteristics with perception of stigma score

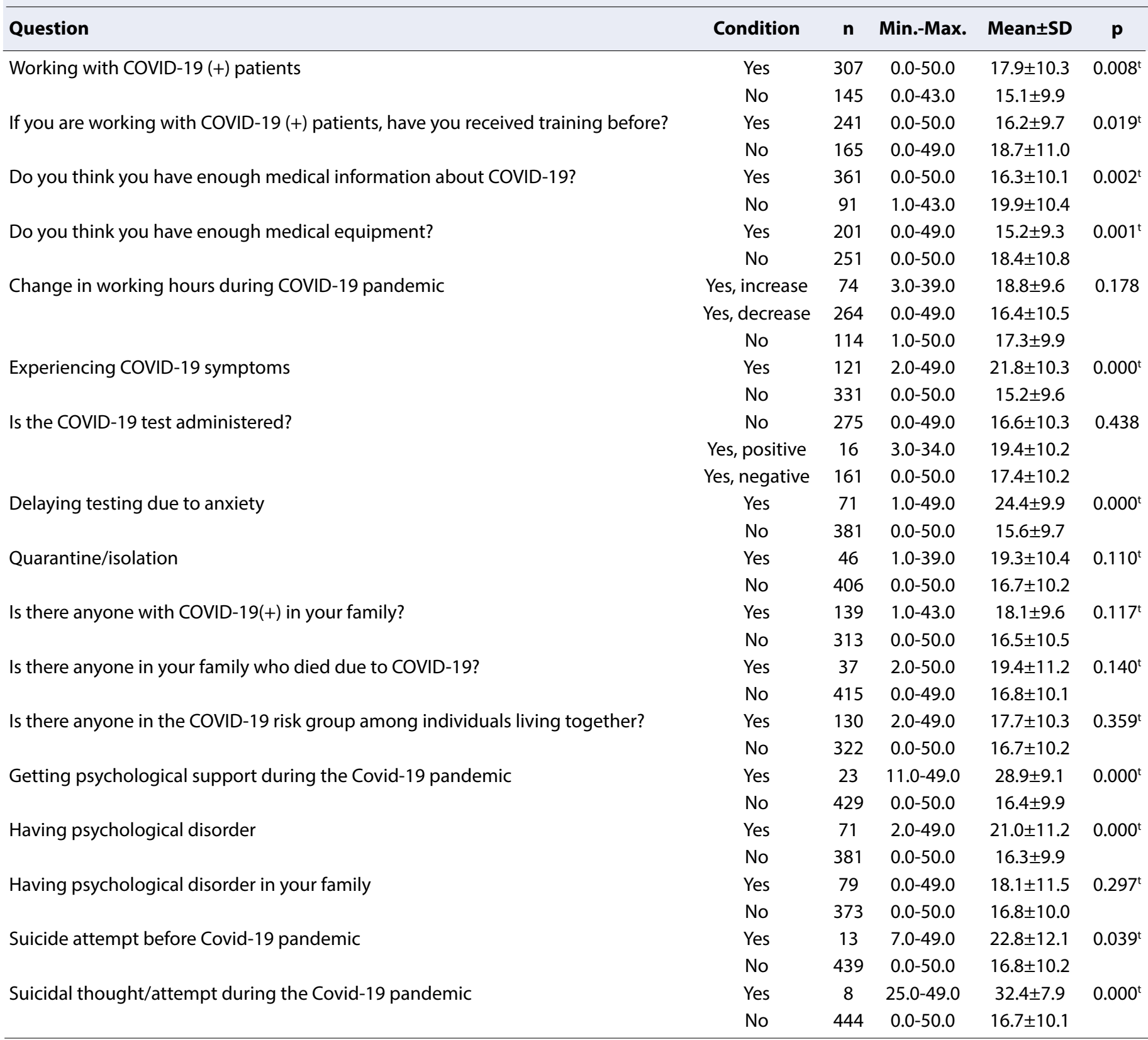

'Student's t-test; One-way Anova; Post hoc: tukey. Min: Minimum; Max: Maximum; SD: Standard deviation; n: number of participants; $p$-value of $<0.05$ was considered statistically significant and shown in bold.

matization experienced symptoms of COVID-19 had a psychological disorder and had suicidal thoughts or attempts before or during the COVID-19 pandemic. There are studies showing that HCWs dealing with the treatment of infectious diseases are stigmatized. ${ }^{[2]}$ In a study that investigated the perception of stigmatization in HCWs, health-care professionals who directly cared for infected SARS patients had higher perceptions of stigmatization than individuals who did not directly care for these patients. ${ }^{[26]}$ Similarly, we found that HCWs working with COVID-19(+) patients felt more stigmatization than individuals not working with these patients.

In a study conducted with 3.011 people in Hong Kong, the disease indicated by the participant group as the most stigmatizing was HIV/AIDS. This was followed by tuberculosis and SARS. ${ }^{[33]}$ The most important factors contributing to the stigma associated with HIV/AIDS are the lethal dimensions of the disease and the fear of transmission through personto-person contact; in the early days of the disease, people had scant information about the disease, or they misunder- 
Table 4. Correlation with the perception of stigmatization with HAD Scale and Psychological Well-Being Scale

\begin{tabular}{lccc}
\hline HAD & & HAD-A & HAD-D \\
\hline Perception of Stigma Score & $r$ & 0.588 & 0.537 \\
& $p$ & 0.000 & 0.000 \\
Psychological Well-Being Scale & & Psychological \\
& \multicolumn{3}{c}{ Well-Being Score } \\
Perception of Stigma Score & $r$ & -0.415 \\
& $p$ & 0.000 & \\
\hline
\end{tabular}

Pearson Correlation. Hospital anxiety depression scale, HAD-A: Anxiety subscale of hospital anxiety depression scale, HAD-D: Depression subscale of hospital anxiety depression scale. $p$-value of $<0.05$ was considered as statistically significant and shown in bold.

Table 5. Correlation with the perception of stigmatization with WHOQOL-BRIEF

\begin{tabular}{|c|c|c|c|c|}
\hline \multicolumn{2}{|l|}{ WHOQOL-BRIEF } & General area & Physical area & Mental area \\
\hline \multicolumn{5}{|l|}{ Perception of } \\
\hline \multirow[t]{2}{*}{ Stigma Score } & $r$ & -0.431 & -0.475 & -0.465 \\
\hline & $p$ & 0.000 & 0.000 & 0.000 \\
\hline WHOQOL-BRIEF & & $\begin{array}{c}\text { Social relations } \\
\text { area }\end{array}$ & $\begin{array}{c}\text { Environment } \\
\text { area }\end{array}$ & \\
\hline \multicolumn{5}{|l|}{ Perception of } \\
\hline \multirow[t]{2}{*}{ Stigma Score } & $r$ & -0.368 & -0.385 & \\
\hline & $p$ & 0.000 & 0.000 & \\
\hline
\end{tabular}

Pearson Correlation. WHOQOL-BRIEF: World Health Organization Quality of Life Scale-Short form. $p$-value of $<0.05$ was considered as statistically significant and shown in bold.

stood issues concerning transmission. ${ }^{[27]}$ Our study found that individuals who think that health-care professionals do not have enough information about COVID-19 have a higher perception of stigma. The COVID-19 pandemic had quickly brought the world into effect in 2019. As effective treatments were found for many infectious diseases in the past, the intensity of stigmatization associated with these diseases decreased over time. ${ }^{[27]}$ Organizing informative in-service seminars on the disease and holding them in public at periodic intervals can reduce stigmatization associated with infectious diseases, such as COVID-19.

The available literature indicates a possible association between HCWs stigmatization and psychological health. ${ }^{[28]}$ Fear of labeling, stigmatization, and discrimination potentially often result in a multitude of psychological problems such as acute fear and anxiety. ${ }^{[29]}$ Similarly, the level of anxiety and depression scores were positively correlated with the level of stigma perception among HCWs in the current study, and these results point to the success of psychological interventions among HCWs. However, in China, individual nurses were reported to refuse any psychological help and deny any problems despite showing excitability, irritability, unwillingness to rest, and signs of psychological distress. ${ }^{[30]}$ The reasons for not seeking psychological help for their problems were the following: they did not want their families to be worried or to be afraid of them bringing the virus home; they did not know how to deal with patients who were unwilling to be quarantined at the hospital, or they did not cooperate with medical measures for whatever reason. ${ }^{[30]}$ By contrast, we found that HCWs who did get psychological support had higher stigma scores. This difference maybe having something to do with different occurrences of the disease over time. China was the first place where COVID-19 pandemic occurred. The first case

Table 6. Correlation with the perception of stigmatization with CSS-BF

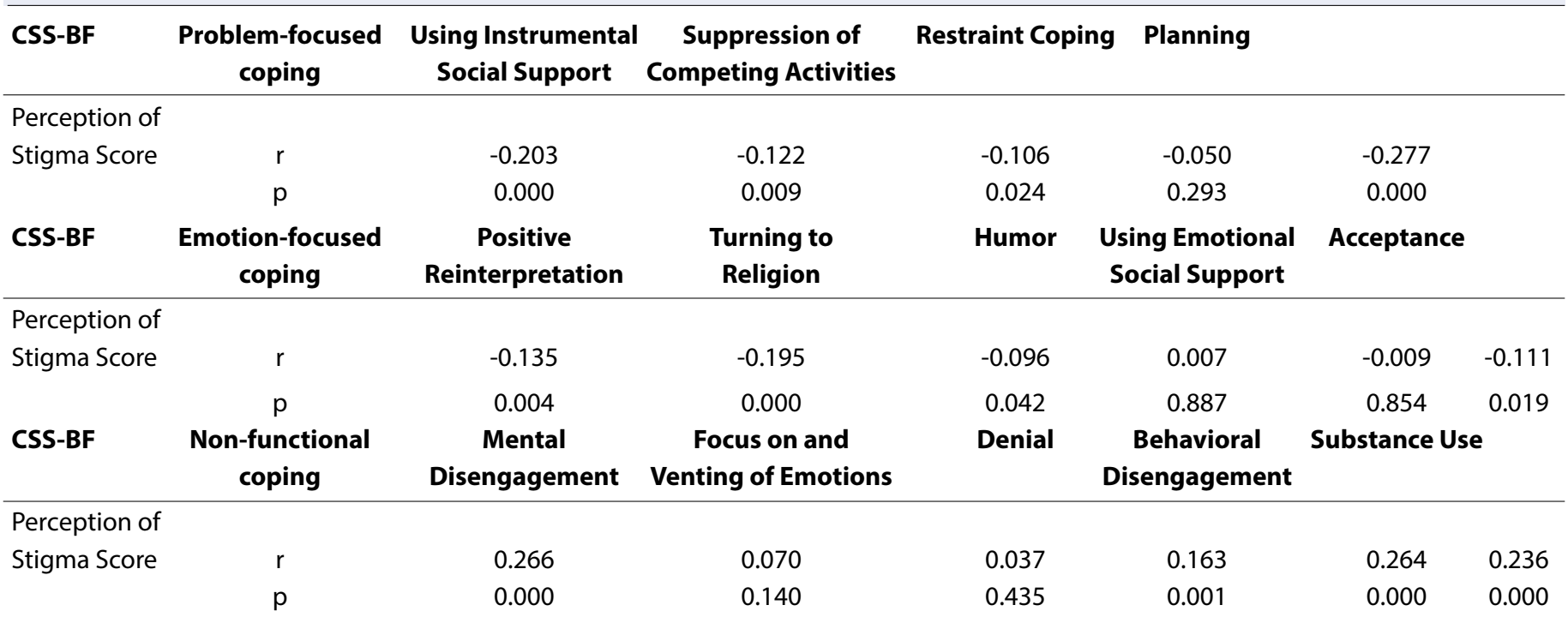

Pearson Correlation. CSS-BF: Coping Styles Scale Brief Form. p-value of $<0.05$ was considered as statistically significant and shown in bold. 
of COVID-19 in Turkey was detected on March 11, 2020, and the first death was reported on March 17. After the first case was detected, radical interventions were implemented by the Turkish government to prevent the spread of the disease. In Turkey, accordingly, previous experiences with COVID-19 led to some psychological interventions being adjusted. RUHSAD, an online therapy outlet for HCWs during the COVID-19 pandemic, is one of these interventions. Telepsychiatry has been used increasingly frequently during the COVID-19 pandemic; turning to our telepsychiatry experts to formulate best processes and messaging might be an important development to address.

There are several significant ways that stigma could potentially affect HCWs. The importance of stigma to quality of life (QOL) is well recognized in HIV research and care: Stigma is included as a domain in the World Health Organisation's HIV-specific measure of QOL. Although the psychosocial and occupational effects of HCWs exposure to blood-borne viral agents, such as $\mathrm{HIV}_{1}^{[31]}$ hepatitis $\mathrm{B}^{[32]}$ and other infectious agents, have been investigated, COVID-19 presents a new challenge for HCWs. This is because COVID-19 is much more communicable in healthcare settings through the droplet-based transmission. In a study by Holzemer et al., ${ }^{[33]}$ HIV-related stigma was claimed to have a more significant negative impact on the quality of life than persons living with HIV infection. Our results showed that perceived stigmatization was negatively correlated with quality of life among HCWs. In a study by Grace et al., physicians' main concerns were the increasing inability to care for non-SARS patients during the SARS (also a droplet-based transmission) outbreaks and personal loss of income. ${ }^{[34]} \mathrm{HCWs}$ who later became infected felt, the loss in the occupational sphere of life as they transitioned from the role of a health-care provider to that of a patient. ${ }^{[35]}$ Due to social isolation, economic versus conclusions, higher COVID-19-related stigmatization seems to lead to a decrease in quality of life.

Being aware of potentially stigmatizing attitudes and behaviors might act as a protective measure against the impact of stigmatization on HCWs. Since stigmatization could affect a person's self-esteem, ${ }^{[36]}$ life satisfaction ${ }^{[37]}$ and professional quality of life (leading to stress, burnout and self-engagement) ${ }^{[33]}$ exploring coping strategies should be emphasized for HCWs. Mok et al. ${ }^{[35]}$ reported that social support, religious practices, faith, prayer, and reflection were the coping responses of their study sample, which included nurses who contracted SARS in Hong Kong. A recent study claimed that a wider social environment was an important topic that needed to be considered during the current COVID-19 pandemic, with an emphasis on raising awareness of the range of possible psychosocial responses, ac- cess to psychological help, self-care, empowering self-support groups and sustained engagement with updated, reliable information about the outbreak. ${ }^{[38]}$ Similarly, in our study sample, HCWs with higher levels of problem-focused and emotion-focused coping had lower stigma perception. Using instrumental social support, suppression of competing activities and planning were the effective problem-focused coping strategies, whereas positive reinterpretation, turning to religion, and acceptance was the effective emotion-focused coping strategies in the current study. However, non-functional coping strategies like denial, behavioral disengagement, and substance abuse increased stigma perception. Chew et al. ${ }^{[38]}$ reported that avoidance as a coping strategy was associated with higher levels of perceived stigma. Avoidance as a coping strategy could paradoxically result in greater stress and emotional exhaustion. ${ }^{[39]}$ The internalization of stigma could also reinforce their avoidance behavior and social isolation. ${ }^{[40]}$ Strategies were psychological interventions like leisure activities and training on how to relax and regular visits by psychological counselors to listen to traumatic experiences from staff members. These strategies might help the problem- and emotion-focused coping strategies with perceived stigma.

Our study has certain limitations, as this study was conducted with cross-sectional and limited sample size. Additionally, in the sample of our study, doctors are more than other health-care professionals. To our knowledge, there is no scale of validity and reliability studies evaluating COVID-19 related stigma. Therefore, the perception of stigmatization on HCWs was examined with the form created by the researchers.

\section{Conclusion}

In conclusion, working with potentially highly infectious patients leads to considerable stigmatization. It is important to study these stigma-related factors and provide preventive measures for health-care workers during pandemics. Our study is crucial because it is one of the few studies investigating the effects of stigmatization on HCWs during the COVID-19 pandemic. Our findings show that stigma is an important predictor affecting mental health and quality of life. Our study may also be significant concerning providing insight into infectious diseases-related stigmatization and the potential consequences of it.

\section{Disclosures}

Ethics Committee Approval: Clinical Research Ethics Committee of University of Health Sciences, Sisli Hamidiye Etfal Research and Training Hospital (approval number: 2782; approval date: 12/05/2020).

Peer-review: Externally peer-reviewed. 
Conflict of Interest: None declared.

Authorship Contributions: Concept - G.T., M.G.T., O.S.O.; Design - G.T., O.B.U.; Supervision - G.T., O.S.O.; Materials - H.M.O.; Data collection \&/or processing - G.T., O.B.U.; Analysis and/or interpretation - O.S.O.; Literature search - G.T., O.S.O.; Writing - G.T., O.B.U., O.S.O., M.G.T.; Critical review - G.T., O.B.U., O.S.O., M.G.T.

\section{References}

1. Brooks SK, Webster RK, Smith LE, Woodland L, Wessely S, Greenberg $\mathrm{N}$, et al. The psychological impact of quarantine and how to reduce it: rapid review of the evidence. Lancet 2020;39:912-20.

2. Koh D, Lim MK, Chia SE, Ko SM, Qian F, Ng V, et al. Risk perception and impact of Severe Acute Respiratory Syndrome (SARS) on work and personal lives of healthcare workers in Singapore: what can we learn? Med Care 2005;43:676-82. [CrossRef]

3. Goulia P, Mantas C, Dimitroula D, Mantis D, Hyphantis T. General hospital staff worries, perceived sufficiency of information and associated psychological distress during the $A / H 1 N 1$ influenza pandemic. BMC Infect Dis 2010;10:322. [CrossRef]

4. Maunder R. The experience of the 2003 SARS outbreak as a traumatic stress among frontline healthcare workers in Toronto: lessons learned. Philos Trans R Soc Lond B Biol Sci 2004;359:111725. [CrossRef]

5. Lai J, Ma S, Wang Y, Cai Z, Hu J, Wei N, et al. Factors Associated With Mental Health Outcomes Among Health Care Workers Exposed to Coronavirus Disease 2019. JAMA Netw Open 2020;3:e203976.

6. Ho CS, Chee CY, Ho RC. Mental Health Strategies to Combat the Psychological Impact of COVID-19 Beyond Paranoia and Panic. Ann Acad Med Singapore 2020;49:155-60.

7. Smereka J, Szarpak L. COVID 19 a challenge for emergency medicine and every health care professional. Am J Emerg Med 2020 Mar 24 [Epub ahead of print], doi:10.1016/j. ajem.2020.03.038. [CrossRef]

8. Maunder R, Hunter J, Vincent L, Bennett J, Peladeau N, Leszcz M, et al. The immediate psychological and occupational impact of the 2003 SARS outbreak in a teaching hospital. CMAJ 2003;168:124551.

9. Sevindik CS, Özer ÖA, Kolat U, Önem R. Internalized stigmatization and its effect on functionality in patients with major depressive disorder or psychotic disorder. Med Bull Sisli Etfal Hosp 2014;48:198-207. [CrossRef]

10. Park JS, Lee EH, Park NR, Choi YH. Mental Health of Nurses Working at a Government-designated Hospital During a MERS-CoV Outbreak: A Cross-sectional Study. Arch Psychiatr Nurs 2018;32:2-6.

11. Rüsch N, Corrigan PW, Wassel A, Michaels P, Olschewski M, Wilkniss $S$, et al. A stress-coping model of mental illness stigma: I. Predictors of cognitive stress appraisal. Schizophr Res 2009;110:59-64.

12. Charles B, Jeyaseelan L, Pandian AK, Sam AE, Thenmozhi M, Jayaseelan $\mathrm{V}$. Association between stigma, depression and quality of life of people living with HIV/AIDS (PLHA) in South India - a community based cross sectional study. BMC Public Health
2012;12:463. [CrossRef]

13. Chang EM, Bidewell JW, Huntington AD, Daly J, Johnson A, Wilson $\mathrm{H}$, et al. A survey of role stress, coping and health in Australian and New Zealand hospital nurses. Int J Nurs Stud 2007;44:135462. [CrossRef]

14. Folkman S, Lazarus RS, Pimley S, Novacek J. Age differences in stress and coping processes. Psychol Aging 1987;2:171-84.

15. Folkman S, Lazarus RS. An analysis of coping in a middle-aged community sample. J Health Soc Behav 1980;21:219-39. [CrossRef]

16. Gao J, Zheng P, Jia Y, Chen H, Mao Y, Chen S, et al. Mental health problems and social media exposure during COVID-19 outbreak. PLoS One 2020;15:e0231924. [CrossRef]

17. Naushad VA, Bierens JJ, Nishan KP, Firjeeth CP, Mohammad OH, Maliyakkal AM, et al. A Systematic Review of the Impact of Disaster on the Mental Health of Medical Responders. Prehosp Disaster Med 2019;34:632-43. [CrossRef]

18. Zigmond AS, Snaith RP. The hospital anxiety and depression scale. Acta Psychiatr Scand 1983;67:361-70. [CrossRef]

19. Aydemir Ö, Güvenir T, Küey L, Kültür S. Validity and reliability of Turkish version of Hospital Anxiety and Depression Scale. Türk Psikiyatri Derg 1997;8:280-7.

20. Diener E, Wirtz D, Biswas-Diener R, Tov W, Kim-Prieto C, Choi D, et al. New Measures of Well-Being. In: Diener $E$, editor. Assessing Well-Being. Dordrecht: Springer; 2009. p. 247-66. [CrossRef]

21. Telef BB. The Adaptation of Psychological Well-Being into Turkish: A Validity and Reliability Study. Hacettepe University Journal of Education 2013;28:374-84.

22. Fidaner H, Elbi H, Fidaner C, Eser SY, Eser E, Göker E. Whoqol-100 and psychometric characteristics of WHOQOL-bref. 3P Psychiatry, Psychology, Psychopharmacology Bulletin 1999;7:23-40.

23. Carver CS, Scheier MF, Weintraub JK. Assessing coping strategies: a theoretically based approach. J Pers Soc Psychol 1989;56:26783. [CrossRef]

24. Bacanlı H, Sürücü M, Ilhan T. Başa Çıkma Stilleri Ölçeği Kısa Formunun (BÇSÖ-KF) Psikometrik Özelliklerinin Incelenmesi: Geçerlik ve Güvenirlik Çalışması. Educational Sciences: Theory \& Practice 2013;13:81-96.

25. Mak WW, Mo PK, Cheung RY, Woo J, Cheung FM, Lee D. Comparative stigma of HIV/AIDS, SARS, and tuberculosis in Hong Kong. Soc Sci Med 2006;63:1912-22. [CrossRef]

26. Verma S, Mythily S, Chan YH, Deslypere JP, Teo EK, Chong SA. Post-SARS psychological morbidity and stigma among general practitioners and traditional Chinese medicine practitioners in Singapore. Ann Acad Med Singapore 2004;33:743-8.

27. Oran NT, Şenuzun F. A loop to be broken in a society: HIV/ AIDS stigma and coping strategies. Journal of Human Sciences 2008;5:1-16.

28. Ramaci T, BarattucciM, Ledda C, Rapisarda V. Social stigma during COVID-19 and its impact on HCWs outcomes. Sustainability 2020;12:1-13. [CrossRef]

29. Zheng W. Mental health and a novel coronavirus (2019-nCoV) in 
China. J Affect Disord 2020;269:201-2. [CrossRef]

30. Chen Q, Liang M, Li Y, Guo J, Fei D, Wang L, et al. Mental health care for medical staff in China during the COVID-19 outbreak. Lancet Psychiatry 2020;7:15-6. [CrossRef]

31. Klimes I. The impact of HIV infection on health care staff and other carers. International Review of Psychiatry 1991;3:429-38.

32. Cockcroft A, Oakley K, Gooch C, Mastin S. Anxiety and perception of risk of HIV and hepatitis B infection among health-care workers reporting accidental exposures to blood and other body fluids. AIDS Care 1994;6:205-14. [CrossRef]

33. Holzemer WL, Human S, Arudo J, Rosa ME, Hamilton MJ, Corless I, et al. Exploring HIV stigma and quality of life for persons living with HIV infection. J Assoc Nurses AIDS Care 2009;20:161-8.

34. Grace SL, Hershenfield K, Robertson E, Stewart DE. The occupational and psychosocial impact of SARS on academic physicians in three affected hospitals. Psychosomatics 2005;46:385-91.

35. Mok E, Chung BP, Chung JW, Wong TK. An exploratory study of nurses suffering from severe acute respiratory syndrome (SARS). Int J Nurs Pract 2005;11:150-60. [CrossRef]
36. Fife BL, Wright ER. The dimensionality of stigma: a comparison of its impact on the self of persons with HIV/AIDS and cancer. J Health Soc Behav 2000;41:50-67. [CrossRef]

37. Greeff M, Uys LR, Wantland D, Makoae L, Chirwa M, Dlamini P, et al. Perceived HIV stigma and life satisfaction among persons living with HIV infection in five African countries: a longitudinal study. Int J Nurs Stud 2010;47:475-86. [CrossRef]

38. Chew QH, Chia FL, Ng WK, Lee WCl, Tan PLL, Wong CS, et al. Psychological and coping responses to COVID-19 amongst residents in training across ACGME-I accredited specialties in Singapore. Psychiatry Res 2020;290:113146. [CrossRef]

39. Marjanovic Z, Greenglass ER, Coffey S. The relevance of psychosocial variables and working conditions in predicting nurses' coping strategies during the SARS crisis: an online questionnaire survey. Int J Nurs Stud 2007;44:991-8. [CrossRef]

40. Gee S, Skovdal M. Public Discourses of Ebola Contagion and Courtesy Stigma: The Real Risk to International Health Care Workers Returning Home From the West Africa Ebola Outbreak? Qual Health Res 2018;28:1499-508. [CrossRef] 